\title{
Produção de Proteína Microbiana e Estimativas das Excreções de Derivados de Purinas e de Uréia em Vacas Lactantes Alimentadas com Rações Isoprotéicas Contendo Diferentes Níveis de Compostos Nitrogenados Não-Protéicos ${ }^{1}$
}

\section{Antonia Santos Oliveira ${ }^{2}$, Rilene Ferreira Diniz Valadares ${ }^{3}$, Sebastião de Campos Valadares Filho ${ }^{3}$, Paulo Roberto Cecon ${ }^{3}$, Luciana Navajas Rennó ${ }^{4}$, Augusto César de Queiroz ${ }^{3}$, Mário Luiz Chizzotti ${ }^{5}$}

\begin{abstract}
RESUMO - Foram objetivos do presente trabalho estimar a produção de proteína microbiana, utilizando-se a excreção total de derivados de purina (DP); comparar as excreções de DP e uréia obtidas a partir de coletas spot de urina com aquelas observadas em coletas de 24 horas; e avaliar as concentrações de N-uréia no plasma e no leite e as excreções de uréia. Utilizaram-se 16 vacas holandesas em quatro quadrados latinos balanceados 4 x 4, distribuídos de acordo com o período de lactação. Cada período experimental teve duração de 21 dias, sendo sete dias de adaptação e 14 dias para as coletas de amostras. As quatro rações experimentais, isoprotéicas, foram formuladas para conter na base da MS $60 \%$ de silagem de milho e $40 \%$ de concentrado. Foram utilizados níveis crescentes de uréia no concentrado: $0 ; 0,7 ; 1,4 ;$ e $2,1 \%$, correspondentes aos níveis de proteína bruta na forma de compostos nitrogenados não-protéicos (NNP) das rações de 2,$22 ; 4,18 ; 5,96$; e $8,09 \%$, respectivamente. O volume urinário foi estimado utilizando amostras de urina obtidas quatro horas após a alimentação (spot), dividindo-se a excreção diária média de creatinina pela concentração de creatinina na urina spot. O volume urinário e as excreções de DP e de uréia, estimados por meio da urina spot, não diferiram daqueles obtidos pela coleta de urina por 24 horas. As produções de N-microbiano estimadas e obtidas apresentaram valores máximos de 198,05 e 196,96 g/dia, nos níveis de compostos nitrogenados não-protéicos de 5,33 e 4,44\%, respectivamente. A concentração de alantoína no leite decresceu linearmente com o aumento dos níveis de NNP na dieta e representou 4,5\% da excreção total de DP. A excreção de creatinina não foi afetada pelos níveis de NNP na dieta $(23,41 \mathrm{mg} / \mathrm{kg} \mathrm{PV})$, enquanto as excreções estimada e obtida de uréia, as concentrações de uréia e N-uréia no plasma e no leite aumentaram linearmente com os níveis de NNP na ração. Concentrações plasmáticas e no leite de N-uréia de 19 a 20 mg\% e 24 a 25 mg\%, respectivamente, representariam valores limites a partir dos quais ocorreriam perdas de compostos nitrogenados.
\end{abstract}

Palavras-chave: creatinina, derivados de purina, compostos nitrogenados não-protéicos, uréia, vacas de leite

\section{Microbial Protein Production, Purine Derivatives and Urea Excretion Estimate in Lactating Dairy Cows Fed Isoprotein Diets with Different Non Protein Nitrogen Compounds Levels}

\begin{abstract}
The objectives of the present work were to estimate the microbial protein production using the total purine derivatives (PD) excretion, to compare the PD and the urea excretions, obtained from spot urine collection with that observed in the 24 hours collection and to evaluate the plasma and milk N-urea and urea urinary excretion. Sixteen Holstein lactating cows were assigned to four 4X4 Latin Square with 3-wk periods in accordance with the lactation period. The four experimental isoproteic diets were formulated to contain $60 \%$ of corn silage and $40 \%$ of corn meal, soybean meal, urea and mineral salt mixture as dry matter basis. Crescent levels of urea in the concentrate $0.0,0.7,1.4$, and $2.1 \%$ corresponded to the crude protein of $2.22,4.18,5.96$ and $8.09 \%$ of non protein nitrogen based compounds (NPN), respectively. The urine collection was also estimated with urine samples obtained four hours post fed (spot), by the relation of the daily mean creatinine excretion and the urine spot creatinine concentration. The urinary volume and PD excretion and urea estimated through the urine spot did not differ from that obtained from $24 \mathrm{~h}$ urine collection. The N-Microbial production estimated and obtained presenting maximum values of 198.05 and $196.96 \mathrm{~g} /$ day with the NPN levels of 5.33 and $4.44 \%$, respectively. The milk allantoin concentration linearly decreased as the NPN increased in the diet and represented 4.5\% of total PD excretion. The creatinine excretion was not influenced by the dietary NPN levels $(23.41 \mathrm{mg} / \mathrm{kg} \mathrm{LW})$, while the estimated and obtained urea excretion, the plasma and milk urea and N-urea concentration linearly increased as the NPN increased in the diet. The plasma and milk N-urea concentration of $19-20 \mathrm{mg} / \mathrm{dL}$ and $24-25 \mathrm{mg} / \mathrm{dL}$, respectively, represented the limit values from that would occur nitrogen compounds losses.
\end{abstract}

Key Words: creatinine, purine derivatives, non protein nitrogen compounds, urea, lactating cows

\footnotetext{
${ }^{1}$ Parte da tese de Mestrado apresentada à Universidade Federal de Viçosa. Projeto parcialmente financiado pela FAPEMIG.

2 Professora da UEMA.

3 Professor da UFV. E.mail: rilene@mail.ufv.br; scvfilho@mail.ufv.br

${ }^{4}$ Estudante de Doutorado.

5 Bolsista de Iniciação Científica.
} 


\section{Introdução}

Maiores demandas para a produção de proteína do leite em relação a outros constituintes levam à maior ênfase no ajustamento do suprimento dietético de proteína e energia para estimular e atender a síntese e produção de leite (HOF et al., 1997). Devido, principalmente, aos altos custos de suplementos protéicos para vacas leiteiras e à possibilidade de comprometimentos reprodutivos, há crescente interesse em minimizar perdas de compostos nitrogenados e, nas condições brasileiras, em reduzir os custos de produção, por meio da utilização de compostos nitrogenados não-protéicos, frequentemente uréia, em substituição ao farelo de soja.

Métodos correntes para medir a produção de compostos nitrogenados microbianos incluem a utilização de marcadores internos - bases purinas e ácido 2,6 diaminopimélico (DAPA) - e externos, como $15 \mathrm{~N}$ e $35 \mathrm{~S}$. Em razão destes métodos necessitarem da utilização de animais fistulados e da determinação do fluxo da matéria seca no abomaso, tem havido interesse crescente no desenvolvimento de técnicas nãoinvasivas para estimar a produção microbiana.

O uso da excreção de derivados de purina (DP) como marcador metabólico da síntese microbiana foi primeiramente proposto por Blaxter e Martin, em 1962, e por Topps e Eliot, em 1965, citados por FUJIHARA et al. (1987), entretanto maiores progressos no estabelecimento de um método relacionando a excreção de DP e a produção microbiana foram feitos recentemente (MAYES et al., 1995).

Hipoxantina, xantina, ácido úrico e alantoína, coletivamente referidos como DP, são produtos do catabolismo das purinas excretadas na urina de ruminantes, sendo a alantoína o maior componente. Os DP originam-se de duas fontes, as purinas absorvidas no intestino delgado $\mathrm{e}$ as endógenas, ou seja, liberadas do metabolismo dos ácidos nucléicos (CHEN e GOMES, 1992).

O método de excreção de DP assume que o fluxo duodenal deácidos nucléicos é essencialmente de origem microbiana e, após digestão intestinal dos nucleotídeos de purinas, as bases adenina e guanina são catabolizadas e excretadas proporcionalmente na urina como DP, principalmente alantoína, e também como xantina, hipoxantina e ácido úrico (PEREZ et al., 1996). Segundo CHEN e GOMES (1992), na urina de bovinos, apenas alantoína e ácido úrico estão presentes, devido à grande atividade de xantina oxidase no sangue e nos tecidos, que converte xantina e hipoxantina a ácido úrico antes da excreção.
A excreção de DP está diretamente relacionada com a absorção de purinas e, conhecendo-se a relação $\mathrm{N}$ purina/ $\mathrm{N}$ total na massa microbiana, a absorção de $\mathrm{N}$ microbiano pode ser calculada a partir da quantidade de purina absorvida, que é estimada a partir da excreção urinária de DP (CHEN e GOMES, 1992).

Segundo MAYES et al. (1995), alguns parâmetros usados nos modelos não foram ainda definidos ou confirmados, entre eles, a recuperação de purinas absorvidas e a relação $\mathrm{N}$ purina/N total (NP/NT) nos microrganismos ruminais. CLARK et al. (1992), CHEN e GOMES (1992), VALADARES FILHO (1995), CARVALHO et al. (1996), DIAS (1999), RENNÓ (1999) e VALADARES et al. (1999) obtiveram relações NP/NT de 13,7; 11,6; 17,6; 15,3; 11,$3 ; 11,7$; e $13,4 \%$, respectivamente.

A excreção urinária de DP pode constituir-se em um método relativamente simples e não-invasivo para estimar a síntese de proteína microbiana, entretanto, de acordo com PEREZ et al. (1996), seu uso necessita de validação, por meio de comparação com estimativas obtidas com outras técnicas. RENNÓ (1999), utilizando 116 observações em 24 bovinos não-castrados, fistulados no rúmen, abomaso e íleo, em cinco experimentos, observou que não houve diferenças significativas entre as produções microbianas determinadas pelo método das bases purinas e pela excreção de DP.

A absorção de amônia através da parede do rúmen é a rota principal para a amônia que não foi assimilada pelos microrganismos, sendo removida da circulação portal pelo fígado, onde entra no ciclo da uréia (VISEK, 1979; LOBLEY et al., 1995).

A uréia constitui a principal forma pela qual os compostos nitrogenados (N) são eliminados do organismo de mamíferos; quando a taxa de síntese de amônia supera a sua utilização pelos microrganismos, observase elevação da concentração de amônia no rúmen, com conseqüente aumento da excreção de uréia e incremento do custo energético da produção de uréia, resultando, dessa forma, em perda de proteína (RUSSEL et al., 1992; MORRISON e MACKIE, 1996).

Vários autores, HENNESSY et al. (1995), THOMSON et al. (1995), VALADARES et al. (1997a) e VALADARES et al. (1999), demonstraram que a concentração plasmática de uréia está positivamente relacionada à ingestão de $\mathrm{N}$.

Em novilhos zebus alimentados com rações contendo $45 \%$ de concentrado e teores de proteína bruta de 7,0 a 14,5\%, VALADARES et al. (1997a) verifi- 
caram, por intermédio de análise de regressão, que a máxima produção microbiana correspondeu a concentrações de N-uréia plasmática (NUP) variando de 13 a $15 \mathrm{mg} / \mathrm{dL}$, o que provavelmente representaria o limite a partir do qual estaria ocorrendo perda de proteína.

A uréia plasmática equilibra-se rapidamente entre os compartimentos líquidos do organismo e também no leite; admite-se que a concentração de N-uréia no leite (NUL) reflete a concentração NUP, (BRODERICK e CLAYTON, 1997) e a concentração de uréia no leite pode ser potente indicador do metabolismo protéico em vacas (ROSELER et al., 1993; SHEPERS e MEIJER, 1998; e JONKER et al., 1998).

Há considerável interesse em se utilizarem concentrações de DP e outros catabólitos nitrogenados no leite e na urina como indicadores do fluxo intestinal de proteína microbiana e da utilização dos compostos nitrogenados dietéticos (SUSMEL et al., 1994).

O método para estimar a produção de proteína microbiana com base na excreção de DP requer coleta total de urina, porém tem potencial de vir a ser simplificado, visando sua utilização em condições de campo. Outras alternativas para estimativa da produção microbiana, em condições de campo, incluiriam as concentrações de alantoína no plasma ou no leite. GIESECKE et al. (1994) descreveram altas correlações entre as concentrações de alantoína no plasma e no leite e a excreção urinária total de alantoína. Entretanto, CHEN et al. (1995) observaram baixa correlação entre a concentração plasmática de DP e a excreção urinária diária de DP em ovinos e GONDA e LINDBERG (1997) concluíram que a excreção de alantoína no leite não seria indicador confiável do fluxo de proteína microbiana para o duodeno em vacas lactantes. Por outro lado, a partir de dez experimentos em que foram utilizadas vacas em lactação, TIMMERMANS JR. et al. (2000) observaram relação positiva entre o fluxo de $\mathrm{N}$ microbiano e a excreção de alantoína no leite.

CHEN e GOMES (1992) afirmaram que, para reduzir erros devidos a variações na produção urinária, as coletas de urina deveriam ser feitas durante pelo menos cinco dias. Diferentes tempos de coleta de urina têm sido descritos, variando em nove dias (SIDDONS et al. 1985), três dias (COTO et al., 1988; GONDA e LINDBERG, 1997) e 24 horas (VALADARES et al., 1997b), sendo que a maioria dos experimentos tem usado animais machos em gaiolas de metabolismo. Poucos experimentos utilizando fêmeas com catéteres foram descritos SUSMEL et al. (1994), VAGNONI et al. (1997) e VALADARES et al. (1997b). Nesses experimentos, o período de coleta variou de 5, 3 e 1-4 dias, respectivamente. Deve ser ressaltado que o uso de catéteres pode representar desconforto, principalmente para animais lactantes e gestantes.

VALADARES et al. (1997b), utilizando quatro vacas em blocos ao acaso com sete períodos de coleta de urina $(2,6,12,24,48,72$ e 96 horas), observaram que não houve diferença significativa em termos de excreção de creatinina entre as coletas com duração de 24, 48 ou 72 horas; as coletas com duração de 96 horas resultaram em menores excreções de creatinina, provavelmente devido a lesões de graus variáveis do trato urinário, vazamento de urina do cateter ou obstrução do cateter, que são problemas freqüentemente relacionados ao emprego dessa técnica por longos períodos. Então, é importante o desenvolvimento de metodologias que permitam o menor tempo possível de coleta de urina, ou até mesmo que tornem desnecessária a coleta total de urina, como as estimativas baseadas na excreção de creatinina utilizando coleta spot de urina.

A creatinina é formada no tecido muscular pela remoção irreversível e não-enzimática de água do fosfato de creatina, originada do metabolismo de aminoácidos (HARPER et al., 1982). Há vários registros na literatura demonstrando ser a excreção de creatinina uma função constante do peso vivo dos animais (ORSKOV e McLEOD, 1982; SUSMEL et al., 1994; VAGNONI et al., 1997; VALADARES et al., 1997a; VALADARES et al., 1999; e RENNÓ, 1999).

É possível a utilização de creatinina como marcador para estimativa do volume urinário, o que permite estimar a excreção de DP e de outros compostos, sem coleta total de urina.

O experimento, utilizando vacas lactantes alimentadas com rações constituídas de $60 \%$ de silagem e $40 \%$ de concentrado na matéria seca (MS) constituído de $0 ; 0,7 ; 1,4 ;$ e $2,1 \%$ de uréia, correspondentes a 2,$22 ; 4,18 ; 5,96 ;$ e $8,09 \%$ de proteína bruta na forma de compostos nitrogenados não-protéicos (NNP), foi conduzido com os objetivos de estimar a produção de proteína microbiana, utilizando-se a excreção total de DP; comparar as excreções de DP e de uréia obtidas a partir de coletas de urina de 24 horas com aquelas 
estimadas a partir de coletas de urina spot; e avaliar as concentrações de uréia e $\mathrm{N}$-uréia no plasma e no leite e a excreção urinária de uréia.

\section{Material e Métodos}

O local do experimento, as instalações, o manejo adotado, a composição e os constituintes das rações e o delineamento experimental foram descritos por OLIVEIRA et al. (2001).

As coletas de urina, com duração de 24 horas, foram realizadas no $20^{\circ}$ dia de cada período experimental, utilizando-se sondas de Folley $\mathrm{n}^{0} 26$, conforme metodologia descrita por VALADARES et al. (1997b). Na extremidade livre da sonda foi adaptada mangueira de polietileno, pela qual a urina era conduzida a um recipiente plástico com tampa contendo $500 \mathrm{~mL}$ de $\mathrm{H} 2 \mathrm{SO} 4$ a $20 \%$. Ao término do período de 24 horas de coleta, a urina foi pesada e homogeneizada e alíquotas de $10 \mathrm{~mL}$ foram diluídas imediatamente em $40 \mathrm{~mL}$ de $\mathrm{H}_{2} \mathrm{SO}_{4}$ a $0,036 \mathrm{~N}$. Estas amostras tiveram o $\mathrm{pH}$ ajustado para valores inferiores a 3 , a fim de evitar destruição bacteriana dos derivados de purinas e precipitação do ácido úrico, e foram armazenadas a $-20^{\circ} \mathrm{C}$ para posteriores análises de creatinina, uréia, alantoína e ácido úrico.

As amostras spot de urina foram obtidas no $15^{\circ}$ dia de cada período experimental, aproximadamente, quatro horas após a alimentação, durante micção espontânea. Foram processadas da mesma forma que as amostras referentes às coletas de 24 horas.

Também no $15^{\circ}$ dia de cada período experimental, foram coletadas amostras de sangue de cada animal, por punção da veia mamária, aproximadamente quatro horas após o fornecimento do alimento, utilizando-se heparina como anticoagulante. As amostras foram conservadas em gelo até a centrifugação a $5.000 \mathrm{rpm}$ durante 15 minutos. O plasma resultante foi armazenado a $-20^{\circ} \mathrm{C}$ para posteriores análises de creatinina e uréia.

As amostras de leite da $1^{\mathrm{a}}$ e $2^{\mathrm{a}}$ ordenha de cada animal foram coletadas no $15^{\circ}$ e $21^{\circ}$ dia de cada período experimental e acondicionadas em caixas de isopor com gelo até a chegada ao laboratório, onde, de imediato, foram analisadas para gordura e proteína. Uma alíquota de $10 \mathrm{~mL}$ de leite foi misturada com $5 \mathrm{~mL}$ de ácido tricloroacético a $25 \%$, filtrada em papel-filtro e armazenada a $-20^{\circ} \mathrm{C}$ para posteriores análises de uréia e alantoína.
A uréia foi determinada na urina, no plasma e no leite desproteinizado e a creatinina, na urina e no sangue, usando-se kits comerciais (Labtest).

A excreção diária média de creatinina, expressa em $\mathrm{mg} / \mathrm{kg}$ PV, foi obtida a partir da excreção diária de creatinina de todos os animais, nos quatros níveis de compostos nitrogenados não-protéicos. $\mathrm{O}$ volume urinário usado para estimar a excreção diária de uréia, alantoína e ácido úrico das amostras de urina spot foi obtido para cada animal, multiplicando-se o respectivo peso vivo pela excreção diária média de creatinina e dividindo-se esse produto pela concentração de creatinina $(\mathrm{mg} / \mathrm{L})$ na urina spot.

As análises de alantoína na urina e no leite desproteinizado e de ácido úrico na urina foram feitas pelo método colorimétrico, conforme metodologia de Fujihara et al. (1987), descrita por CHEN e GOMES (1992).

A excreção total de DP foi calculada pela soma das quantidades de alantoína e ácido úrico excretado na urina e das quantidades de alantoína excretadas no leite, expressas em $\mathrm{mmol} / \mathrm{dia}$.

As purinas absorvidas (X, mmol/dia) foram calculadas a partir da excreção de derivados de purinas (Y, mmol/dia), por intermédio da equação $\mathrm{Y}=0,85 \mathrm{X}+0,385 \mathrm{PV} 0,75$, em que 0,85 é a recuperação de purinas absorvidas como derivados de purina e 0,385 PV0,75, a contribuição endógena para a excreção de purinas (Verbic et al., 1990, citados por CHEN e GOMES, 1992).

A síntese ruminal de compostos nitrogenados (Y, gN/dia) foi calculada em função das purinas absorvidas (X, mmol/dia), utilizando-se uma modificação da equação descrita por CHEN e GOMES, (1992), substituindo-se a relação Npurina:Ntotal nas bactérias de 0,116 para 0,134 , conforme VALADARES et al., 1999: $\mathrm{Y}=70 \mathrm{X} /$ $0,83 \times 0,134 \times 1000$, em que 70 é o conteúdo de $\mathrm{N}$ de purinas $(\mathrm{mgN} / \mathrm{mol}) ; 0,134$, a relação $\mathrm{N}$ purina: $\mathrm{N}$ total nas bactérias (VALADARES et al., 1999); e 0,83 , a digestibilidade das purinas microbianas.

Os resultados foram avaliados por meio de análises de variância e regressão, utilizando-se o Sistema de Análises Estatísticas e Genéticas SAEG (UNIVERSIDADE FEDERAL DE VIÇOSA - UFV, 1998). Os critérios utilizados para escolha do modelo foram o coeficiente de determinação $\left(\mathrm{R}^{2}\right)$, que foi calculado como a relação entre a soma de quadrado da regressão e a soma de quadrado de tratamento e a significância observa- 
da por meio do teste $\mathrm{F}$, a $5 \%$ de probabilidade. Os quatro quadrados latinos foram analisados em conjunto. Foi utilizada análise de variância para comparar as médias observadas com as estimadas, por meio da utilização do teste "t" de Student, a 5\% de probabilidade.

\section{Resultados e Discussão}

Observam-se, na Tabela 1, os dados referentes à comparação de médias obtidas e estimadas do volume urinário e às excreções urinárias de uréia, alantoína e ácido úrico, purinas totais, purinas absorvidas e Nmicrobiano. Não houve diferença significativa para nenhuma das variáveis.

A excreção diária de creatinina não foi afetada $(\mathrm{P}>0,05)$ pelos níveis de compostos nitrogenados não protéicos (NNP) na dieta, sendo, em média, de $23,41 \mathrm{mg} / \mathrm{kg}$ PV. VALADARES et al. (1999) também não obtiveram diferenças entre os volumes urinários estimados e obtidos para dietas com teores de 20,50 e $65 \%$ de concentrado e entre as excreções observadas e estimadas de alantoína e derivados de purina (DP) total para dietas contendo 20 a $50 \%$ de concentrado. Assim, coleta spot de urina parece adequada para substituir coleta total de urina.

As médias estimadas e obtidas referentes ao volume urinário, às quantidades de uréia, alantoína e ácido úrico excretado na urina, à quantidade de alantoína excretada no leite, às purinas totais, purinas absorvidas e à produção de N-microbiano, além dos coeficientes de variação e das probabilidades, são

Tabela 1 - Comparação das médias diárias obtidas e estimadas dos volumes urinários $(V)$, excreções urinárias de uréia $(U)$ e alantoína (ALA), de ácido úrico $(A C)$ e purinas totais $(P T)$, purinas absorvidas (PA) e compostos nitrogenados microbianos (Nmic)

Table 1 - Comparison among daily obtained and estimated means of urinary volume $(V)$, urinary excretions of urea $(U)$ and alantoin (ALA), uric acid (UA) and total purines (TP), absorbed purines (AP) and microbial nitrogen compounds (Nmic)

\begin{tabular}{lccc}
\hline $\begin{array}{l}\text { Variáveis } \\
\text { Variable }\end{array}$ & $\begin{array}{c}\text { Obtido } \\
\text { Obtained }\end{array}$ & $\begin{array}{l}\text { Estimado } \\
\text { Estimated }\end{array}$ & $\mathrm{P}$ \\
\hline $\mathrm{V}(\mathrm{L})$ & 12,52 & 12,47 & $\mathrm{~ns}$ \\
$\mathrm{U}(\mathrm{mg} / \mathrm{kgPV})$ & 295,19 & 295,91 & $\mathrm{~ns}$ \\
ALA $(\mathrm{mmol})$ & 262,96 & 238,17 & $\mathrm{~ns}$ \\
AC $(\mathrm{mmol})$ & 29,40 & 29,24 & $\mathrm{~ns}$ \\
PT $(\mathrm{mmol})$ & 298,96 & 279,38 & $\mathrm{~ns}$ \\
PA $(\mathrm{mmol})$ & 307,27 & 285,50 & $\mathrm{~ns}$ \\
Nmic $(\mathrm{g})$ & 193,39 & 179,69 & $\mathrm{~ns}$ \\
\hline
\end{tabular}

apresentadas na Tabela 2. Constam da Tabela 3 as respectivas equações de regressão, os coeficientes de determinação $\left(\mathrm{r}^{2} / \mathrm{R}^{2}\right)$ e os pontos críticos de inclusão de NNP nas rações, quando for o caso.

Os teores de NNP dietéticos não afetaram $(\mathrm{P}>0,05)$ o volume urinário estimado, porém tiveram efeito linear crescente $(\mathrm{P}<0,05)$ sobre o volume urinário obtido, que apresentou aumento de, aproximadamente, $0,6 \mathrm{~L}$ para cada $1 \%$ de NNP na dieta $\left(\mathrm{r}^{2}=0,8920\right)$. Níveis crescentes de proteína nãodegradada no rúmen (PNDR) na dieta de vacas lactantes também afetaram linearmente o volume urinário, conforme observado por MOSCARDINI et al. (1998). Esses autores atribuíram o aumento do volume urinário ao efeito do teor total de $\mathrm{PB}$ da dieta, entretanto, no presente experimento, as rações eram isoprotéicas.

As excreções urinárias estimadas e obtidas de uréia variaram de 217,05 a $358,80 \mathrm{mg} / \mathrm{kgPV}$ e de 208,03 a $374,46 \mathrm{mg} / \mathrm{kgPV}$, respectivamente, e demonstraram comportamento linear crescente $(\mathrm{P}<0,05)$, em função dos níveis de NNP na dieta, possivelmente indicando diminuição no aproveitamento dietético. $\mathrm{O}$ aumento da excreção de uréia, em função dos teores de PB da dieta, foi observado por vários autores, destacando-se TOPPS e ELLIOT (1967), SUSMEL et al. (1994) e VALADARES et al (1997a). VALADARES et al. (1997a) sugeriram que a reabsorção de uréia não é um percentual constante da fração filtrada, possibilitando maior conservação de uréia a baixas ingestões e maior excreção a altas ingestões de proteína dietética.

Houve efeito quadrático dos teores de NNP na dieta $(\mathrm{P}<0,05)$ sobre as excreções urinárias estimadas e obtidas de alantoína, obtendo-se valores máximos de 258,12 e $297,09 \mathrm{mmol} /$ dia para os níveis de 5,20 e 4,75\% de NNP, respectivamente. Estes valores foram menores que os observados por VALADARES et al. (1999), de 369 a $535 \mathrm{mmol} / \mathrm{dia}$, para vacas com produção diária média de $40 \pm 7 \mathrm{~kg}$ de leite. A proporção de alantoína excretada na urina, em relação ao total excretado de derivados de purinas, foi, em média, de 85,4 e $87,8 \%$ para os valores estimados e obtidos, respectivamente, estando próxima à obtida por VAGNONI et al. (1997), de 86,6\%, e por SHINGFIELDT e OFFER (1998), de 82\%.

A excreção estimada de ácido úrico não foi influenciada $(\mathrm{P}>0,05)$ pelos teores de NNP na dieta, apresentando valor médio de $29,32 \mathrm{mmol} /$ dia; entretanto, a excreção obtida de ácido úrico 
Tabela 2 - Médias diárias estimadas $(E)$ e obtidas $(O)$ dos volumes urinários $(V)$, excreções urinárias de uréia (U), alantoína (ALA) e ácido úrico $(A C)$, excreção de alantoína no leite (ALAL), purinas totais (PT), purinas absorvidas (PA) e compostos nitrogenados microbianos (Nmic), em função dos níveis de compostos nitrogenados não-protéicos (NNP) das rações, coeficientes de variação $(\mathrm{CV})$ e probabilidades $(\mathrm{P})$ referentes aos efeitos linear $(\mathrm{L})$ e quadrático $(\mathrm{Q})$

Table 2 - Estimated (E) and obtained (O) daily means of urinary volume (V), urinary excretions of urea (U), alantoin (ALA) and uric acid (UA), alantoin excretion in the milk (ALAM), total purines (TP), absorbed purines (AP) and microbial nitrogen compounds (Nmic), in function of the non protein nitrogen compounds (NNP) levels, coefficients of variation (CV) and probabilities (P) in relation to the linear ( $L)$ and quadratic (Q) effects

\begin{tabular}{|c|c|c|c|c|c|c|c|}
\hline \multirow[t]{2}{*}{$\begin{array}{l}\text { Variáveis } \\
\text { Variable }\end{array}$} & \multicolumn{4}{|c|}{$\begin{array}{l}\text { Teores de NNP }(\%) \\
\text { NNP levels }\end{array}$} & \multirow[t]{2}{*}{ CV\% } & \multicolumn{2}{|c|}{$\mathrm{P}$} \\
\hline & 2,22 & 4,18 & 5,96 & 8,09 & & $\mathrm{~L}$ & Q \\
\hline VE(L) & 12,20 & 10,83 & 13,24 & 13,61 & 32,51 & $\mathrm{~ns}$ & $\mathrm{~ns}$ \\
\hline $\mathrm{VO}(\mathrm{L})$ & 11,07 & 11,48 & 13,01 & 14,42 & 15,60 & 0,0109 & $\mathrm{~ns}$ \\
\hline UE (mg/kgPV) & 217,05 & 285,94 & 321,86 & 358,80 & 29,96 & 0,0012 & $\mathrm{~ns}$ \\
\hline $\mathrm{UO}(\mathrm{mg} / \mathrm{kgPV})$ & 208,03 & 279,65 & 314,63 & 374,46 & 29,58 & 0,0002 & $\mathrm{~ns}$ \\
\hline $\operatorname{ALAE}(\mathrm{mmol})$ & 220,74 & 252,87 & 256,47 & 222,61 & 22,67 & 0,0447 & 0,0434 \\
\hline ALAO (mmol) & 258,89 & 278,23 & 303,89 & 216,66 & 28,82 & 0,0329 & 0,0209 \\
\hline ACE (mmol) & 29,87 & 31,90 & 29,74 & 25,76 & 35,23 & $\mathrm{~ns}$ & $\mathrm{~ns}$ \\
\hline $\mathrm{ACO}(\mathrm{mmol})$ & 30,84 & 34,48 & 28,80 & 23,79 & 30,63 & 0,0196 & $\mathrm{~ns}$ \\
\hline ALAL (mmol) & 13,47 & 12,76 & 12,33 & 11,50 & 6,15 & 0,0250 & $\mathrm{~ns}$ \\
\hline PTE (mmol) & 257,31 & 294,77 & 303,93 & 259,88 & 20,28 & 0,0308 & 0,0290 \\
\hline PTO (mmol) & 302,94 & 325,83 & 321,23 & 251,96 & 20,54 & 0,0694 & 0,0400 \\
\hline PAE (mmol) & 255,43 & 301,27 & 317,01 & 265,59 & 23,87 & 0,0286 & 0,0292 \\
\hline $\mathrm{PAO}(\mathrm{mmol})$ & 311,80 & 339,18 & 333,56 & 251,74 & 23,43 & 0,0674 & 0,0386 \\
\hline $\operatorname{NmicE}(\mathrm{gN})$ & 160,77 & 189,62 & 199,53 & 167,16 & 23,87 & 0,0286 & 0,0292 \\
\hline $\mathrm{NmicO}(\mathrm{gN})$ & 196,24 & 213,48 & 209,94 & 158,44 & 23,43 & 0,0674 & 0,0386 \\
\hline
\end{tabular}

decresceu 1,4041 $\mathrm{mmol} /$ dia para cada $1 \%$ de aumento de NNP na dieta.

Constatou-se comportamento linear decrescente $(\mathrm{P}<0,05)$ para a excreção de alantoína no leite, que variou de 13,47 a $11,50 \mathrm{mmol} / \mathrm{dia}$, quando o NNP aumentou de 2,22 para 8,09\% da dieta, provavelmente refletindo a redução na produção de leite descrita, para estes animais, por OLIVEIRA et al. (2000); já que GONDA e LINDBERG (1997) concluíram que a produção de leite foi importante fator na determinação da excreção de alantoína no leite. Correlação positiva entre a produção de N-microbiano e a excreção de alantoína no leite foi descrita por TIMMERMANS JR. et al. (2000), entretanto, no presente experimento, esta relação não foi significativa.

A excreção de alantoína no leite em relação à excreção total de derivados de purinas (DP) foi de 4,5\%, estando de acordo com os valores descritos por VALADARES et al. (1999) e CHEN e GOMES (1992), que obtiveram excreção de alantoína no leite representando 4,2 a $5,7 \%$ e $5 \%$, respectivamente, da excreção total de DP. Por outro lado, SUSMEL et al. (1995) relataram que a alantoína no leite foi equivalente a 10,6 a 10,9\% da alantoína urinária, enquanto GONDA e LINDBERG (1997) obtiveram valores bem menores, 0,63 a 1,34\% da alantoína urinária.

As excreções totais estimada e obtida de DP demonstraram comportamento quadrático $(\mathrm{P}<0,05)$, em função dos teores de NNP na dieta, apresentando valores máximos de 303,70 e 330,40 mmol/dia para os níveis de 5,23 e 4,34\% de NNP, respectivamente. Relação quadrática em função do NNP da dieta também foi obtida para as purinas absorvidas $(\mathrm{P}<0,05)$ e para as produções de $\mathrm{N}$-microbiano no rúmen, estimadas e obtidas. Valores máximos de 314,66 e $344,26 \mathrm{mmol} /$ dia de purinas absorvidas estimadas e obtidas foram calculados para 5,34 e 4,44\% de NNP na dieta, respectivamente; as produções estimadas e obtidas de N-microbiano apresentaram os máximos de 198,05 e 196,96 gNmic/dia, correspondentes a 5,34 e $4,44 \%$ de NNP na dieta, respectivamente. A produção de N-microbiano obtida por VALADARES et al. (1999), a partir da excreção de derivados de purinas, variou de 278 a $419 \mathrm{gNmic} / \mathrm{dia}$, enquanto VAGNONI et al. (1997) obtiveram variação de 308 a $362 \mathrm{gNmic} /$ dia.

$\mathrm{Na}$ Tabela 4, são apresentadas as médias das concentrações de uréia no plasma, $\mathrm{N}$-uréia plasmática, uréia no leite, $\mathrm{N}$-uréia no leite e $\mathrm{N}$-proteína do leite e a relação $\mathrm{N}$-uréia/N-total do leite, correspondentes 
Tabela 3 - Equações de regressão ajustadas do volume urinário diário obtido (VO), das excreções urinárias diárias estimadas $(E)$ e obtidas $(O)$ de uréia $(U)$, alantoína $(A L A)$, ácido úrico $(A C)$, alantoína no leite $(A L A L)$ e das purinas totais (PT), das purinas absorvidas (PA) e dos compostos nitrogenados microbianos (Nmic), em função dos níveis de inclusão de NNP nas rações, coeficientes de determinação $\left(r^{2} / R^{2}\right)$ e pontos críticos (PC)

Table 3 - Linear or quadratic regression equations of obtained daily urinary volume (V), estimated (E) and obtained (O) daily urinary excretions of urea (U), alantoin (ALA) and uric acid (UA), alantoin excretion in the milk (ALAM) and total purines (TP), absorbed purines $(A P)$ and microbial nitrogen compounds (Nmic), in function of the non protein nitrogen compounds (NNP) levels, coefficients of determination $\left(R^{2} / r^{2}\right)$ and critical points $(C P)$

\begin{tabular}{llcc}
\hline $\begin{array}{l}\text { Variável } \\
\text { Variable }\end{array}$ & \multicolumn{1}{c}{$\begin{array}{c}\text { Regressão } \\
\text { Regression }\end{array}$} & $\mathrm{R}^{2} / \mathrm{r}^{2}$ & $\mathrm{PC}$ \\
\hline $\mathrm{VO}(\mathrm{L})$ & $\hat{\mathrm{Y}}=9,43782+0,598714 \mathrm{NNP}$ & 0,8920 & - \\
$\mathrm{UE}(\mathrm{mg} / \mathrm{kgPV})$ & $\hat{\mathrm{Y}}=174,576+23,7331 \mathrm{NNP}$ & 0,9683 & - \\
$\mathrm{UO}(\mathrm{mg} / \mathrm{kgPV})$ & $\hat{\mathrm{Y}}=153,247+27,5721 \mathrm{NNP}$ & 0,9446 & - \\
ALAE $(\mathrm{mmol})$ & $\hat{\mathrm{Y}}=143,602+44,0224 \mathrm{NNP}-4,2309 \mathrm{NNP}^{2}$ & 0,9987 & 5,20 \\
ALAO. $(\mathrm{mmol})$ & $\hat{\mathrm{Y}}=144,180+64,3747 \mathrm{NNP}-6,78388 \mathrm{NNP}^{2}$ & 0,8700 & 4,75 \\
ACO $(\mathrm{mmol})$ & $\hat{\mathrm{Y}}=36,6239-1,4041 \mathrm{NNP}$ & 0,6883 & - \\
ALAL $(\mathrm{mmol})$ & $\hat{\mathrm{Y}}=14,1885-0,326913 \mathrm{NNP}$ & 0,9931 & - \\
PTE $(\mathrm{mmol})$ & $\hat{\mathrm{Y}}=160,108+54,9238 \mathrm{NNP}-5,25205 \mathrm{NNP}^{2}$ & 0,9900 & 5,23 \\
PTO $(\mathrm{mmol})$ & $\hat{\mathrm{Y}}=216,040+51,4326 \mathrm{NNP}-5,79281 \mathrm{NNP}^{2}$ & 0,9700 & 4,34 \\
PAE $(\mathrm{mmol})$ & $\hat{\mathrm{Y}}=135,558+67,1422 \mathrm{NNP}-6,29258 \mathrm{NNP}^{2}$ & 0,9700 & 5,34 \\
PAO $(\mathrm{mmol})$ & $\hat{\mathrm{Y}}=208,748+61,0018 \mathrm{NNP}-6,86524 \mathrm{NNP}^{2}$ & 4,44 \\
NmicE $(\mathrm{gN})$ & $\hat{\mathrm{Y}}=85,3204+42,2593 \mathrm{NNP}-3,96055 \mathrm{NNP}^{2}$ & 0,9700 & 5,34 \\
NmicO $(\mathrm{gN})$ & $\hat{\mathrm{Y}}=131,3860+38,3945 \mathrm{NNP}-4,32098 \mathrm{NNP}^{2}$ & 0,9900 & 4,44 \\
\hline
\end{tabular}

Tabela 4 - Concentrações médias de uréia plasmática (UP), N-uréia plasmática (NUP), uréia no leite (UL),expressas em $\mathrm{mg} / \mathrm{dL}$, N-uréia no leite (NUL), expressa em mg/dL e g/dia, N-proteína no leite (NPL), expressa em g/dia, e a relação $\mathrm{N}$-uréia:N-total no leite (NUL/NPL), em função dos níveis de compostos nitrogenados não-protéicos (NNP) das rações, coeficientes de variação $(C V)$ e probabilidades $(P)$ referentes aos efeitos linear $(L)$ e quadrático $(Q)$

Table 4 - Plasma urea concentrations (PU), plasma N-urea (NUP), urea in the milk (UM), expressed in mg/dL, N-urea in the milk (NUL), expressed in $\mathrm{mg} / \mathrm{dL}$ and $\mathrm{g} /$ day), $\mathrm{N}$-protein in the milk (NUM), express in $\mathrm{g} /$ day, and $\mathrm{N}$-urea:total $\mathrm{N}$ in the milk ratio, in function of the non protein nitrogen compounds (NNP) levels, coefficients of variation (CV) and probabilities (P) in relation to the linear (L) and quadratic (Q) effects

\begin{tabular}{|c|c|c|c|c|c|c|c|}
\hline \multirow[t]{2}{*}{$\begin{array}{l}\text { Variáveis } \\
\text { Variable }\end{array}$} & \multicolumn{4}{|c|}{$\begin{array}{l}\text { Teores de NNP (\%) } \\
\text { NNP levels }\end{array}$} & \multirow[t]{2}{*}{ CV\% } & \multicolumn{2}{|c|}{$\mathrm{P}$} \\
\hline & 2,22 & 4,18 & 5,96 & 8,09 & & $\mathrm{~L}$ & Q \\
\hline $\mathrm{UP}(\mathrm{mg} / \mathrm{dL})$ & 35,26 & 41,84 & 44,11 & 49,52 & 19,54 & 0,0001 & $\mathrm{~ns}$ \\
\hline $\mathrm{NUP}(\mathrm{mg} / \mathrm{dL}$ & 16,43 & 19,50 & 20,56 & 23,08 & 19,54 & 0,0001 & $\mathrm{~ns}$ \\
\hline $\mathrm{UL}(\mathrm{mg} / \mathrm{dL})$ & 47,41 & 53,41 & 58,68 & 58,92 & 15,80 & 0,0047 & $\mathrm{~ns}$ \\
\hline NUL (mg/dL) & 22,09 & 24,89 & 27,34 & 27,46 & 15,80 & 0,0047 & $\mathrm{~ns}$ \\
\hline NUL (g/dia) & 4,48 & 4,93 & 5,19 & 4,82 & 17,63 & $\mathrm{~ns}$ & $\mathrm{~ns}$ \\
\hline NPL (g/dia) & 110,05 & 105,42 & 98,45 & 90,29 & 6,12 & 0,0009 & $\mathrm{~ns}$ \\
\hline NUL/NPL (\%) & 4,05 & 4,60 & 5,18 & 5,35 & 17,04 & 0,0010 & $\mathrm{~ns}$ \\
\hline
\end{tabular}

aos teores de 2,22; 4,18; 5,96; e 8,09\% de NNP nas dietas, os $\mathrm{CV}$ e as probabilidades (P) para os efeitos linear e quadrático. Constam da Tabela 5 as respectivas equações de regressão.

As concentrações de uréia no plasma e N-uréia no plasma e no leite apresentaram comportamento linear crescente, em função dos níveis de NNP na dieta, variando de 35,52 a 49,52 mg/dL; 16,43 a 23,08 mg/dL; e
22,09 a 27,46 mg/dL, respectivamente. BAKER et al. (1995) obtiveram variações de NUP e NUL, 16,0 a 23,4 $\mathrm{mg} / \mathrm{dL}$ e 15,1 a 23,3 mg/dL respectivamente, que foram atribuídas ao aumento da porcentagem de $\mathrm{PB}$ da dieta e ao desbalanço de PDR ou PNDR. No presente experimento, o aumento de NNP em dietas isoprotéicas parece diminuir a eficiência da utilização de amônia no rúmen, daí resultando em aumento da concentração de NUP. 
Tabela 5 - Equações de regressão ajustadas para as concentrações de uréia plasmática (UP), N-uréia plasmática (NUP), uréia no leite (UL) e N-uréia no leite (NUL), a quantidade de N-proteína no leite (NPL) e a relação $\mathrm{N}$-uréia: $\mathrm{N}$-total no leite (NUL:NPL), em função dos níveis de NNP das rações, e coeficientes de determinação $\left(r^{2}\right)$

Table 5 - Linear regression equations for the plasma urea concentrations (PU), plasma N-urea (NUP), urea in the milk (UM) and N-urea in the milk (NUM), the N-protein amount in the milk (NPM) and Nurea:total N in the milk ratio, in function of the dietary non protein nitrogen compounds (NNP) levels, coefficients of determination $\left(r^{2}\right)$

\begin{tabular}{llc}
\hline $\begin{array}{l}\text { Variável }(\mathrm{Y}) \\
\text { Variable }\end{array}$ & \multicolumn{1}{c}{$\begin{array}{c}\text { Regressão } \\
\text { Regression }\end{array}$} & $\mathrm{r}^{2}$ \\
\hline $\mathrm{UP}(\mathrm{mg} / \mathrm{dL})$ & $\hat{\mathrm{Y}}=30,7806+2,3284 \mathrm{NNP}$ & 0,9758 \\
$\mathrm{NUP}(\mathrm{mg} / \mathrm{dL})$ & $\hat{\mathrm{Y}}=14,3438+1,08503 \mathrm{NNP}$ & 0,9758 \\
$\mathrm{UL}(\mathrm{mg} / \mathrm{dL})$ & $\hat{\mathrm{Y}}=44,2229+2,03102 \mathrm{NNP}$ & 0,8782 \\
NUL $(\mathrm{mg} / \mathrm{dL})$ & $\hat{\mathrm{Y}}=20,6079+0,946457 \mathrm{NNP}$ & 0,8782 \\
NPL $(\mathrm{g} / \mathrm{dia})$ & $\hat{\mathrm{Y}}=118,5340-3,41923 \mathrm{NNP}$ & 0,9882 \\
NUL/NPL $(\%)$ & $\hat{\mathrm{Y}}=3,61993+0,22999 \mathrm{NNP}$ & 0,9419 \\
\hline
\end{tabular}

Admitindo-se, como ótimos para a produção de $\mathrm{N}$-microbiano, os teores de 4,4 a 5,3\% de NNP na dieta e substituindo-os nas equações de regressão correspondentes, as concentrações no plasma (NUP) e no leite (NUL) de N-uréia de 19 a $20 \mathrm{mg} \%$ e 24 a $25 \mathrm{mg} \%$, respectivamente, representariam limites a partir dos quais estariam ocorrendo perdas de $\mathrm{N}$ dietético. Valores limítrofes menores para NUP, de 13,52 a $15,5 \mathrm{mg} / \mathrm{dL}$, foram observados por VALADARES et al. (1997a) para novilhos mestiços.

A quantidade de N-protéico no leite variou de 110,05 a 90,29 g/dia, demonstrando comportamento linear decrescente significativo. A relação NUL:Nproteína no leite foi aumentada linearmente pelos níveis de NNP na dieta e variaram de 4,05 a 5,35\% $(\mathrm{P}<0,001)$.

\section{Conclusões}

A excreção urinária de DP pode constituir um método não-invasivo para estimar a produção microbiana ruminal em vacas de leite.

O volume urinário pode ser estimado a partir de amostras spot de urina.

Os níveis de inclusão de NNP de 5,33 e 4,44\% corresponderam às máximas produções microbianas estimadas e obtidas de 198,05 e 196,96 g N-mic/dia, respectivamente.

Concentrações de $\mathrm{N}$-uréia no plasma e no leite de 19 a 20 e 24 a $25 \mathrm{mg} \%$, respectivamente, representariam limite para a utilização de $\mathrm{N}$ dietético.

\section{Referências Bibliográficas}

BAKER, L.D., FERGUSON, J.D., CHALUPA, W. 1995. Responses in urea and true protein of milk to different protein feeding schemes for dairy cows. J. Dairy Sci., 78: 2424- 2434.

BRODERICK, G.A., CLAYTON, M.K. 1997. A statistical evaluation of animal and nutritional factors influencing concentrations of milk urea nitrogen. J. Dairy Sci., 80:2964-2971.

CARVALHO, A.U. Niveis de concentrado na dieta de zebuinos: consumo, digestibilidade e eficiência microbiana. Viçosa, MG: UFV, 1996. 112p. Tese (Doutorado em Zootecnia) Universidade Federal de Viçosa, 1996.

CHEN, X.B., GOMES, M.J. 1992. Estimation of microbial protein supply to sheep and cattle based on urinary excretion of purine derivatives- an overview of technical details. INTERNATIONAL FEED RESEARCH UNIT. Rowett Research Institute. Aberdeen, UK.(Occasional publication). $21 \mathrm{p}$.

CHEN, X.B., MEJIA, A.T., KYLE, D.J., ORSKOV, E.R. 1995. Evaluation of the use of purine derivative: creatinine ratio in spot urine and plasma samples as an index of microbial protein supply in ruminants: studies in sheep. J. Agric. Sci., 125:137-143.

CLARK, J.H., KLUSMEYER, T.H., CAMERON, M.R. 1992. Microbial protein synthesis and flows of nitrogen fractions to the duodenum of dairy cows. J. Dairy Sci., 75(8):23042323.

COTO, G., RODRIGUES, M.M., INFANTE, F.P. et al. 1988. The effect of increasing consumption of concentrates, creatinine, creatine and allantoin in the urine of rams fed hay. Cuban J. Agric. Sci., 22(2):279-284.

DIAS, H.L.C. Consumo, digestibilidade e eficiência microbiana em novilho $F_{1}$ LimousinxNelore alimentados com dietas contendo cinco niveis de concentrado. Viçosa, MG: UFV, 1999. 76p Dissertação (Mestrado em Zootecnia) - Universidade Federal de Viçosa, 1999.

FUJIHARA, T., ØRSKOV, E.R., REEDS, P.J. et al. 1987. The effect of protein infusion on urinary excretion of purine derivatives in ruminants nourished by intragastric nutrition. J. Agric. Sci., 109:7-12.

GIESECKE, D., EHRENTREICH, L., STANGASSINGER, M. 1994. Mammary and renal excretion of purine metabolites in relation to energy intake and milk yield in dairy cows. J. Dairy Sci., 77: 2376-2381.

GONDA, H.L., LINDBERG, J.E. 1997. Effect of diet on milk allantoin and its relationship with urinary allantoin in dairy cows. J. Dairy Sci., 80:364-373.

HARPER, H.A., RODWELL, V.W., MAYES, P.A. 1982. Manual de química fisiológica. 5.ed. São Paulo: Atheneu. $736 \mathrm{p}$.

HENNESSY, D.W., KOHUN, P.J., WILLIANSON, P.J. et al. 1995. The effect of nitrogen and protein supplementation on feed intake, growth and digestive function of steers with different Bos indicus, Bos taurus genotypes when fed a low quality grass hay. Aust. J. Res., 46(6):1121-1236.

HOF, G., VERVOORN, M.D., LENAERS, P.J. et al. 1997. Milk urea nitrogen as a tool to monitor the protein nutrition of diry cows. J. Dairy Sci., 80:3333-3340.

JONKER, J.S., KOHN, R.A., ERDMAN, R.A. 1998. Using milk urea nitrogen to predict nitrogen excretion and utilization efficiency in lactating dairy cows. J. Dairy Sci., 81:2681-2692.

LOBLEY, G.E., CONNELL, A., LOMAX, M.A. et al. 1995. The effect of nitrogen and protein supplementation on feed 
intake, growth and digestive function of steers with different Bos taurus genotypes when fed a low quality grass hay. Br. J. Nutr., 73(5):667-685.

MAYES, R.W., DOVE, H., CHEN, X.B. et al. Advances in the use of faecal and urinary markers for measuring diet composition, herbage intake and nutrient utilization in herbivores. In: INTERNATIONAL SYMPOSIUM OF THE NUTRITION OF HERBIVORES, 4, 1995, Paris. Proceedings... Paris: INRA, 1995. p.381-406.

MERCHEN, N.R., BOURQUIN, L.D. 1994. Processes of digestion and factors influencing digestion of forage-based diets by ruminants. In: FAHEY JR., G.C. (Ed.) Forage quality, evaluation and utilization. Madison. p.564-602.

MORRISON, M.E., MACKIE, R.I. 1996. Nitrogen metabolism by ruminal microorganism:current understanding and future perspectives. Aust. J. Agric. Res., 47(2):227-246.

MOSCARDINI, S., WRIGHT, T.C., LUIMES, P.H. et al. 1998. Effects of rumen-undegradable protein and feed intake on purine derivate and urea nitrogen:comparison with predictions from the Cornell Net Carbohydrate and protein system. J. Dairy Sci., 81(9):2421-2329.

OLIVEIRA, A.S., VALADARES, R.F.D., VALADARES FILHO, S.C. et al. 2001. Consumo, digestibilidade aparente, produção e composição do leite em vacas alimentadas com quatro níveis de compostos nitrogenados não protéicos. Rev. bras. zootec., 30(4): 1358-1366.

ØRSKOV, E.R., MACLEOD, N.A. 1982. The determination of the minimal nitrogen excretion in steers and dairy cows and its physiological and practical implications. Br. J. Nut., 47:625-636.

PEREZ, J.F., BALCELlS, J., GUADA, J.A. et al. 1996. Determination of rumen microbial-nitrogen production in sheep: a comparison of urinary purine excretion with methods using ${ }^{15} \mathrm{~N}$ and purine bases as markers of microbial-nitrogen entering the duodenal. Br. J. Nut., 75:699-709.

RENNÓ, L.N. Produção de proteína microbiana utilizando derivados de purina na urina, concentração plasmática de uréia e excreções de uréia e creatinina em novilhos. Viçosa, MG: UFV, 1999. 95p. Dissertação (Mestrado em Zootecnia) - Universidade Federal de Viçosa 1999.

ROSELER, D. K., FERGUSON, J. D. , SNIFFEN, C. J. 1993. Dietary protein degradability effects on plasma and milk urea nitrogen and milk nonprotein nitrogen in holstein cows. J. Dairy Sci., 76:525-534.

RUSSEL, J.B., O'CONNOR, J.D., FOX, D.J. et al. 1992. A net carbohydrate and protein system for evaluating cattle diets: I. Ruminal fermentation. J. Anim. Sci., 70:425-441.

SCHEPERS, A.J., MEIJER, R.G.M. 1998. Evaluation of the utilization of dietary nitrogen by dairy cows based on urea concentration in milk. J. Dairy Sci., 81:579-584.

SHINGFIELDT, K.J., OFFER, N.W. 1998. Evaluation of milk alantoin excretion as an index of microbial protein supply in lactating dairy cows. J. Anim. Sci., 67:371-385.

SIDDONS, R.C., NOLAN, J.V., BEEVER, D.E. et al. 1985. Nitrogen digestion and metabolism in sheep consuming diets containing contrasting forms and levels of N. Br J. Nutr., 54(1):175-187.
SUSMEL, P., STEFANON, B., PLAZZOTA, E. et al. 1994. The effect of energy and protein intake on the excretion of purine derivatives. J. Agric. Sci., 123:257-266.

SUSMEL, P., SPANGHERO, M., STEFANON, B. et al. 1995. Nitrogen balance and partitioning of some nitrogen catabolites in milk and purine of lactating cows. Livest. Prod. Sci., 44:207-209.

THOMSON, D.U., PRESTON, R.L., BARTLE, S.J. 1995. Influence of protein source and level on the performance, plasma urea nitrogen and carcass characteristics of finishing beef steers. J. Anim. Sci., 73(1):257. (Abstract)

TOPPS, J.H., ELLIOT, R.C. 1967. Partition of nitrogen in the urine of African sheep given a variety of low-protein diets. Anim. Prod., 9(1):219-227.

TIMMERMANS JR., S.J., JOHNSON, L.M., HARRISON, J.H. et al. 2000. Estimation of the flow of microbial nitrogen to the duodenum using milk uric acid or allantoin. J. Dairy Sci., 83:1286-1299.

UNIVERSIDADE FEDERAL DE VIÇOSA - UFV. 1998. Sistema de análises estatísticas e genéticas - SAEG. Versão 8.0. Viçosa, MG. (Manual do usuário). 150p.

VAGNONI, D.B., BRODERICK, M.K., CLAYTON, R.D. et al. 1997 Excretion of purine derivatives by Holstein cows abomasally infused with incremental amounts of purines. J. Dairy Sci., 80:1695-1702.

VALADARES, R.F.D., GONÇALVES, L.C., SAMPAIO, I.B. et al. 1997a. Níveis de proteína em dietas de bovino. 4. Concentrações de amônia ruminal e uréia plasmática e excreções de uréia e creatinina. R. Bras. Zootec., 26(6):12701278.

VALADARES, R.F.D., GONÇALVES, L.C., SAMPAIO, I.B. et al. 1997b. Metodologia de coleta de urina em vacas utilizando sondas de folley. R. Bras. Zootec., 26(6):12791282.

VALADARES, R.F.D., BRODERICK, G.A., VALADARES FILHO, S.C. etal. 1999. Effect of replacing alfafa with high moisture corn on ruminal protein synthesis estimated from excretion of total purine derivatives. J. Dairy Sci., 82:2686-2696.

VALADARES FILHO, S.C. Eficiência de síntese de proteína microbiana, degradação ruminal e digestibilidade intestinal da proteína bruta, em bovinos. In: SIMPÓSIO INTERNACIONAL SOBRE EXIGÊNCIAS NUTRICIONAIS DE RUMINANTES, 1995, Viçosa. Anais... Viçosa: UFV/DZO, 1995. P.1259-1263.

VISEK, W.J. 1979. Ammonia metabolism, urea cycle capacity and their biochemical assessment. Nutr. Rev., 3799:273-282. 